\title{
Comprehensive Genetic and Mutation Analysis of Familial Dementia with Lewy Bodies Linked to 2q35-q36
}

\author{
Bram Meeus ${ }^{\mathrm{a}, \mathrm{b}, \mathrm{c}}$, Karen Nuytemans ${ }^{\mathrm{a}, \mathrm{b}, \mathrm{c}}$, David Crosiers ${ }^{\mathrm{a}, \mathrm{c}, \mathrm{d}, \mathrm{e}}$, Sebastiaan Engelborghs ${ }^{\mathrm{c}, \mathrm{f}, \mathrm{g}}$, \\ Karin Peeters $^{\mathrm{a}, \mathrm{b}, \mathrm{c}}$, Maria Mattheijssens ${ }^{\mathrm{a}, \mathrm{b}, \mathrm{c}}$, Ellen Elinck ${ }^{\mathrm{a}, \mathrm{b}, \mathrm{c}}$, Ellen Corsmit ${ }^{\mathrm{a}, \mathrm{b}, \mathrm{c}}$, \\ Peter Paul De Deyn ${ }^{\mathrm{c}, \mathrm{f}, \mathrm{g}}$, Christine Van Broeckhoven ${ }^{\mathrm{a}, \mathrm{b}, \mathrm{c}, *}$ and Jessie Theuns ${ }^{\mathrm{a}, \mathrm{b}, \mathrm{c}}$ \\ ${ }^{a}$ Neurodegenerative Brain Diseases Group, Department of Molecular Genetics, VIB, Antwerpen, Belgium \\ ${ }^{\mathrm{b}}$ Laboratory of Neurogenetics, Institute Born-Bunge, Antwerpen, Belgium \\ ${ }^{\mathrm{c}}$ University of Antwerp, Antwerpen, Belgium \\ ${ }^{\mathrm{d}}$ Laboratory of Neurobiology, Institute Born-Bunge, Antwerpen, Belgium \\ ${ }^{\mathrm{e}}$ Division of Neurology, University Hospital Antwerp, Antwerpen, Belgium \\ ${ }^{\mathrm{f}}$ Laboratory of Neurochemistry and Behavior, Institute Born-Bunge, Antwerpen, Belgium \\ ${ }^{\mathrm{g}}$ Memory Clinic and Division of Neurology, ZNA Middelheim, Antwerpen, Belgium
}

\begin{abstract}
The second most frequent form of neurodegenerative dementia after Alzheimer's disease is dementia with Lewy bodies (DLB). Since informative DLB families are scarce, little is presently known about the molecular genetic etiology of DLB. We recently mapped the first locus for DLB on chromosome 2q35-q36 in a multiplex Belgian family, DR246, with autopsy-proven DLB pathology in a region of $9.2 \mathrm{Mb}$. Here, we describe the ascertainment of additional DR2 46 family members and significant finemapping of the DLB locus to $3.3 \mathrm{Mb}$ based on informative meiotic recombinants. Extensive sequencing of the 42 positional candidate genes within the DLB region did not identify a simple pathogenic mutation that co-segregated with disease in family DR246. Also high resolution analysis of copy number variations in the DLB locus did not provide evidence for a complex mutation. In conclusion, we confirmed the DLB locus at 2q35-q36 as a genetic entity but candidate gene-based sequencing and copy number variation analysis did not identify the pathogenic mutation in family DR246. Other detection strategies will be needed to reveal the underlying mutation explaining the linkage of DLB to 2q35-q26. Possibly the disease mutation in this family acts through a more complex mechanism than generally envisaged for monogenic disorders. Nevertheless, identifying the first familial DLB gene is likely to contribute an entry point into the pathogenic cascades underlying DLB pathology.
\end{abstract}

Keywords: Chromosome 2, dementia with Lewy bodies, mutation analyses, positional candidate genes

Supplementary data available online: http://dx.doi.org/10.3233/JAD-2010-1356

${ }^{*}$ Correspondence to: Prof. Dr. Christine Van Broeckhoven PhD DSc, Neurodegenerative Brain Diseases Group, VIB - Department of Molecular Genetics, University of Antwerp - CDE, Universiteitsplein 1, B-2610 Antwerpen, Belgium. Tel.: +32 3265 1001; Fax: +32 3265 1012; E-mail: christine.vanbroeckhoven@ molgen.vibua.be.

\section{INTRODUCTION}

Dementia with Lewy bodies (DLB) accounts for the second most frequent form of neurodegenerative dementia after Alzheimer's disease (AD), with an estimated prevalence up to $30.5 \%$ among dementia patients [1, 2]. Despite the high frequency of DLB, very little is known about its genetic etiology. This is most probably 
due to the observation that most patients have no obvious family history of DLB. Only a few families have been reported in which a mixed phenotype of dementia and parkinsonism is inherited in either an autosomal dominant [3-8] or recessive [9] manner. Therefore, it is generally accepted that the genetic etiology of DLB is complex, and most probably results from the interplay of genetic and environmental risk factors.

In the past decade, molecular genetic studies have revealed genetic variants (both simple mutations and copy-number variations (CNVs)) associated with DLB in genes previously reported to be implicated in classic forms of AD (A $\beta P P$ [10], PSEN1 [11], PSEN2 [12], $P R N P$ [13]) or in Parkinson's disease (PD) (SNCA [1416], SNCB [17], LRRK2 [18,19], GBA [20-23]). However, mutations in these genes explain only a small number of clinically diagnosed DLB patients. Moreover, familial co-segregation with disease was often not obtained for these mutations, resulting in incomplete genetic evidence for pathogenicity.

Multiplex families segregating neurodegenerative brain diseases have been instrumental in the identification of the major dementia and PD genes. For DLB, we have identified one such informative, pathology confirmed, Belgian family DR246, and have subsequently mapped by genome-wide linkage analysis a novel locus for autosomal dominant DLB in chromosome band 2q35-q36 [3]. Here, we aimed at refining the DLB locus by ascertaining additional family members of the Belgian DLB family DR246 and examining segregation of additional simple tandem repeat (STR) markers for meiotic recombinants. Further, we performed an extensive mutation analysis of all genes in the refined DLB locus by direct sequencing in combination with high density array-CGH experiments.

\section{MATERIALS AND METHODS}

\section{Subjects}

The clinical and pathological characteristics of the DLB family DR246 that was ascertained in Flanders, the Flemish speaking region of Belgium, have been described in detail [3]. A series of unrelated FlandersBelgian control individuals $(N=360$; mean age at inclusion: $59.3 \pm 14.4$ years (range 37-94)) were also ascertained. The control group consisted of subjects without neurological or psychiatric antecedents and subjects without organic disease involving the central nervous system, based on clinical examination. Ve- nous blood samples of all participants aged $\geqslant 18$ years were obtained for genomic DNA (gDNA) extraction and EBV transformation of lymphocytes using standard laboratory protocols.

The clinical and genetic studies were approved by the Medical Ethical Committees of ZNA Middelheim, University Hospital of Antwerp and University of Antwerp, and written informed consent was obtained from all participants.

\section{STR genotyping}

For STR genotyping, gDNA was amplified in $20 \mu \mathrm{l}$ multiplex PCR (mPCR) reactions using standard optimized conditions and fluorescently labeled primers. PCR products were separated and analyzed on an ABI3730 DNA Analyzer (Applied Biosystems, Foster City, CA) and genotypes were assigned using in-house developed LGV genotyping software (http://www. vibgeneticservicefacility.be). Pedcheck was used to check for potential Mendelian inconsistencies [24].

\section{Linkage analyses}

For statistical analyses, DLB was treated as a dichotomous, autosomal dominant trait with agedependent penetrance. A cumulative risk curve was calculated and seven penetrance classes were defined using mean age at onset (AAO) in the family and assuming a maximum disease penetrance of $90 \%$ [3]. We performed parametric linkage analyses with MLINK for two-point and LINKMAP for multipoint linkage analysis, both from the Linkage program version 5.2 [25]. All patients of family DR246 with dementia and/or parkinsonism were considered affected in the linkage calculations. The phenotype of individual II.2 (Fig. 1), a potential obligate carrier, was considered unknown. Two-point and multi-point LOD scores were calculated in the extended linkage pedigree using the same parameters as in the simulation study with marker allele frequencies set equal [3].

\section{Annotation of DLB locus}

We annotated the entire genomic sequence of the minimal candidate region using public databases ('NCBI MapViewer', 'Ensembl', 'UCSC Human Genome Browser'). Data mining efforts ('Entrez Gene', 'Genecards') provided detailed up-to-date information on gene function and expression patterns. Next, we sorted the candidate genes using 'Endeavour' [26], 


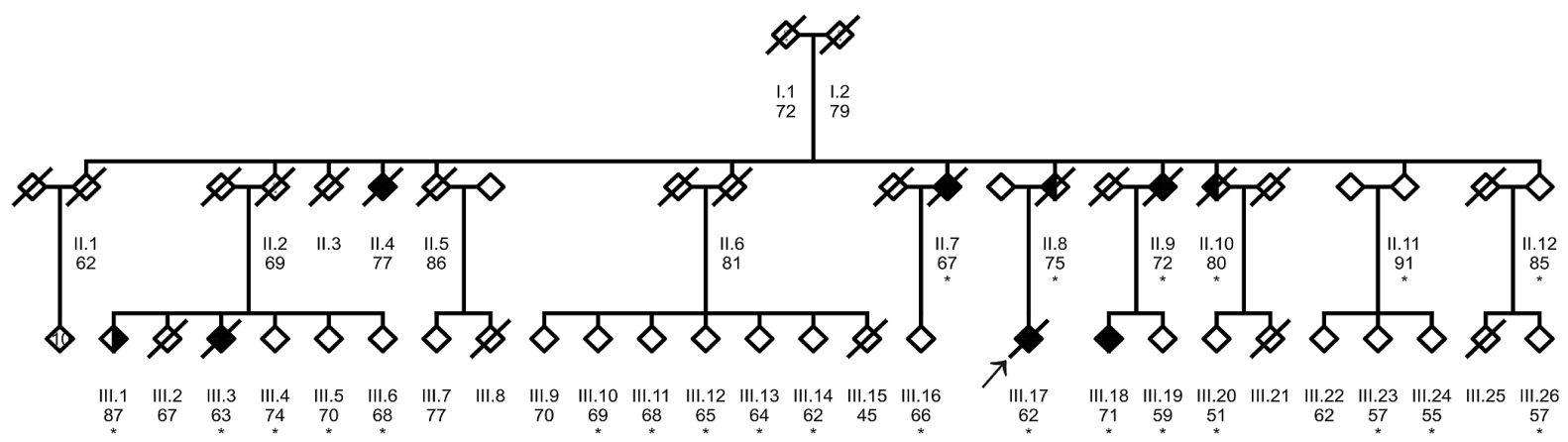

Fig. 1. Pedigree of family DR246. Left-filled symbols represent patients with dementia, right-filled symbols patients with parkinsonism. Patients with dementia and parkinsonism are indicated with filled symbols. Open symbols represent unaffected individuals or at-risk individuals with unknown clinical phenotype; question marks indicate obligate carriers or deceased individuals with unknown clinical phenotype. The Roman numbers specify generations. The arrow indicates the index patient III.17 of family DR246 with pathologically confirmed DLB on autopsied brain. Numbers below the symbols denote age at onset for patients and either age at last examination or age at death for unaffected individuals, at-risk individuals with unknown clinical phenotype or obligate carriers. An asterisk (*) indicates individuals of whom we retrieved blood samples.

a generic prioritization tool that is useful for the candidate disease genes as well as candidate members of biological pathways and processes. This ranking contemplates sequence similarity, protein domains, protein interactions, pathways, gene expression, etc. We used the following input information to prioritize: Homo sapiens as species of interest, a set of training genes consisting of well-established genes known to be involved in dementia or PD and a set of candidate genes, residing in the candidate region. The output generated by 'Endeavour' are prioritized lists of candidate genes; rankings per data source or one global ranking obtained by fusion of the ranking per data source. Since 'Endeavour' uses 'Ensembl' as its gene source database for a genomic region of interest, we compared and complemented this list by annotating the candidate region in 'NCBI MapViewer'. As such, a combined total of 42 candidate genes, known as well as predicted ones, were identified and prioritized for mutation analyses.

\section{Gene-based sequencing analysis}

We sequenced all positional candidate genes on gDNA of 1 patient (III.1), 1 at-risk family member carrying the disease haplotype (III.16), as well as 2 noncarriers (III.10 and III.23) of family DR246 as controls (Fig. 1). Intronic primers flanking the coding and noncoding exons as well as primers for predicted promoter regions (UCSC genome browser) were designed using either Primer Express ${ }^{\circledR} \mathrm{v} 2.0$ (Applied Biosystems, Foster City, CA) or Primer3 (Primer sequences available upon request). PCR and sequencing reactions were performed using empirically defined reaction conditions.
Sequence variations in each gene were detected and scored with the software package 'novoSNP', a bioinformatics tool for automatic detection of sequence variations [27], and visually checked according to GLP principles. We determined the frequency of potential disease causing variants in an extended control group by direct sequencing using the same primers and reaction conditions as described for the mutation analyses.

\section{Copy number variation detection}

Oligo-based comparative genomic hybridization (array-CGH) experiments were performed using custom made high-density arrays (NimbleGen, Madison WI, USA) containing validated 50-mer oligonucleotides of the $3.3 \mathrm{Mb}$ candidate region on chromosome 2 with a median probe spacing of $25 \mathrm{bp}$. gDNA of one patient (III.1) of family DR246 and one at-risk individual (III.19) carrying the disease haplotype was hybridized and compared to gDNA of an independent reference individual (Promega female human gDNA; provided by NimbleGen). Raw data were analyzed with CGHcall [28]. Next, signals consistent for both disease haplotype carriers were selected and priority was given based on 1) the probability score of being a real CNV generated by CGHcall; 2) the number of successive probes indicating the presence of a copy number variation (CNV); and 3) the location of the CNV, with highest priority to $\mathrm{CNVs}$ affecting functional candidate genes or regulatory regions, lowest priority to $\mathrm{CNVs}$ located far outside genes.

CNVs detected with array-CGH were confirmed/ excluded by SYBR $^{\circledR}$ Green real-time PCR (qPCR) 
assays on the ABI Prism 7900HT Sequence Detection System (Applied Biosystems, Foster City, CA, USA). qPCR amplicons were designed in selected potential CNV regions with Primer Express ${ }^{\circledR}$ V2.0 (Applied Biosystems) and normalized against a in-house developed reference amplicon in human RNAseP. A total of $50 \mathrm{ng}$ gDNA of 3 patients (III.1, III.17 and III.18), 1 at-risk individual (III.19), 3 unaffected family members not carrying the disease haplotype (III.4, III.5, and III.10) and the independent reference individual (Promega female human gDNA) was amplified in duplicate using the universal amplification protocol (Applied Biosystems). The standard curve method was used to quantify amplification of the different amplicons. Dosage quotients (DQ) were calculated as the ratio of normalized quantities of the test (members of family DR246) and reference samples. A DQ $>1.3$ was considered indicative for a genomic duplication and a DQ $<0.7$ indicative for a heterozygous deletion.

\section{RESULTS}

\section{Expanding the Flanders-Belgian DLB family DR246}

We had identified a three-generation family, DR246, with prominent dementia and parkinsonism consistent with the clinical diagnosis of probable DLB, which was autopsy confirmed for the index patient (III.17) (Fig. 1) [3]. Since the initial report on this DLB family, clinical follow-up of individual III.18 revealed that in this patient dementia emerged in addition to the previously reported parkinsonian features. Moreover, we were able to ascertain two additional at-risk relatives: one healthy sibling of the proband (II.11) aged 91 years and one of his children (III.24) aged 58 years. Detailed information on clinical phenotype and family history is now available for eight patients in family DR246 resulting in a mean onset age of $70.7 \pm 6.3$ years (range: 62-80 years) and mean duration of disease of $11.5 \pm$ 5.2 years. Biomaterials are available for the eight patients and 16 at-risk individuals.

\section{Finemapping of the DLB locus}

In family DR246, we have localized the genetic defect to a region of $9.2 \mathrm{Mb}$ in chromosome band 2q35-q36 using an STR-based genome-wide linkage approach [3]. The newly ascertained family members II.11 and III.24 of family DR246 were genotyped for 24 STR markers spanning the DLB locus between D2S433 and chr2q36.3-8 (Fig. 2). Haplotype analysis identified a meiotic recombinant in the healthy 91 year old sibling II.11 (Fig. 2). The current age of this at-risk individual exceeded the mean onset age in family DR246 by 20.3 years, leaving a very low probability of 0.01 (based on 0.89 risk in penetrance class 7 (age $>85$ years) with a maximum penetrance of 0.90 ) that this individual might still acquire the disease at a later age.

Next we selected three STR markers - D2S2197, D2S313, and D2S360 - flanking the meiotic recombination site from the Marshfield gender-averaged genetic map (http://research.marshfieldclinic.org/genetics/) to genotype all 24 available members of family DR246. Haplotype analysis defined a minimal candidate region of $3.3 \mathrm{Mb}$ between markers D2S433 (II.8) and D2S2197 (II.11) (Fig. 2). Including the additional relatives and STR markers, we obtained a maximum multipoint LOD score of 3.02 at D2S1242.

\section{Mutation analysis of DLB candidate genes}

Annotation of the $3.3 \mathrm{Mb}$ candidate region prioritized 42 candidate genes using 'Endeavour' [26] to 33 known protein-coding (Fig. 3), two miRNA genes (Fig. 3) and seven predicted genes (LOC616644, ENSG198069, ENSG208071, ENSG208073, ENSG200029, ENSG176320, LOC402120), which we extensively analyzed for simple mutations by direct genebased sequencing. We identified in total 309 genetic variants, 242 known and 67 novel variants, which comprised 28 non-synonymous variants, 47 synonymous variants, 42 variations in either 5' or 3' untranslated regions, 142 intronic variations, 45 variations in 5 ' or 3' regulatory regions, and 5 variations in the exons of predicted genes (Supplementary Table 1; available online: http://www.j-alz.com/issues/20/vol20-1.html\# supplementarydata).

Seven heterozygous genetic variants in four genes segregated on the disease haplotype in family DR246 (Table 1). Analysis in a series of 360 FlandersBelgian control individuals indicated that all seven variants were either common (DNAJB2, ATG9A, and $A N K Z F 1$ variants) or rare (MAF $<1 \%$; OBSL1 p.Ala1477Thr and $O B S L 1$ g.70629303G $>$ A relative to NT_005403.16) polymorphisms. Both rare OBSL1 polymorphisms were identified in a heterozygous state in six (mean AAI: $63.5 \pm 9.8$ years; male/female ratio: 2:4) and two (mean AAI: 66 years \pm 7.1 years; male/female ratio: $0: 2$ ) control individuals respectively. 


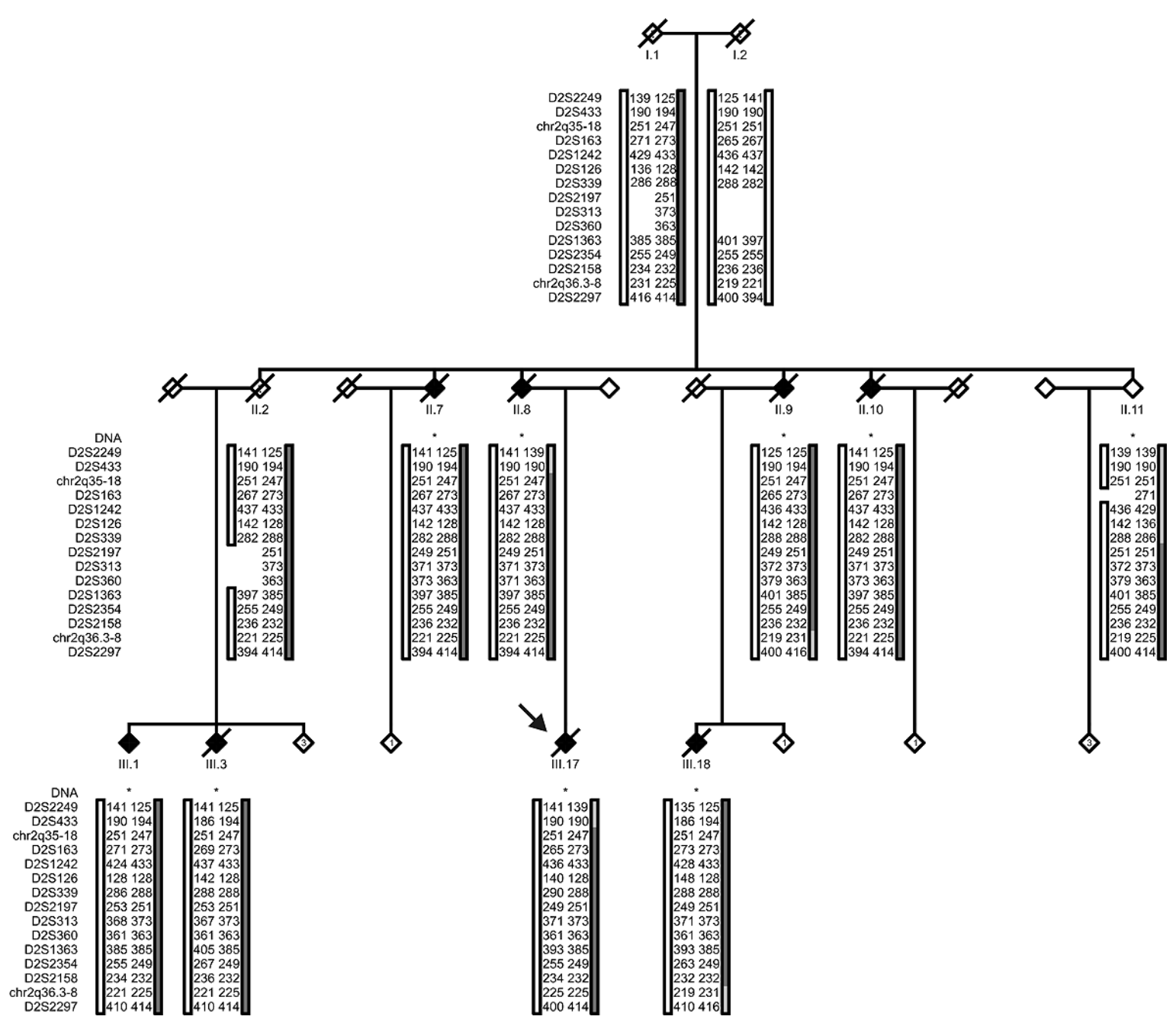

Fig. 2. Linkage pedigree of family DR246. Filled symbols represent patients with dementia, parkinsonism, or both. Haplotypes are based on the selection of 15 informative STR markers on 2q35-q36 of 27 STR markers analyzed. The disease haplotype was arbitrarily set for I.1, and numbers in diamonds indicate the number of genotyped at-risk individuals. Haplotypes for individuals I.1, I.2 and II.2 were inferred from their siblings. For confidentiality reasons haplotypes are only shown for patients and obligate carriers.

\section{CNV detection by array-CGH}

Since disease-related sequence variants were absent in all 42 positional candidate genes, we conducted high resolution array-CGH experiments to detect a potential dosage mutation causing DLB in the Belgian family. We analyzed the raw data of III.1 and III.19 using CGHcall [28] and prioritized signals suggestive for a CNV for verification with QPCR. As such, we identified 11 regions with a potentially relevant CNV; 2 intronic deletions (NHEJ1 intron5: 7 probes $-140 \mathrm{bp}$ and ACCN4 intron1: 9 probes - $171 \mathrm{bp}), 1$ exonic deletion (EPHA4 exon10: 13 probes - 234bp), 7 intergenic deletions (number of successive probes ranging from
7 (140 bp) to 65 (1359 bp)) and 1 intergenic duplication $(8$ probes $-207 \mathrm{bp}$ ) in potential regulatory regions. None of these CNVs were confirmed by real-time PCR.

\section{DISCUSSION}

Though there is a strong genetic contribution to risk for DLB, little is known about the genetic etiology of DLB. Identification of disease genes for DLB has been hampered by the near absence of informative DLB families. We, however, were able to identify the first DLB locus in a 3-generation Flanders-Belgian DLB family, DR246, on chromosome $2 q$ by a genome-wide link- 
Table 1

Genetic variants segregating with DLB in family DR246

\begin{tabular}{|c|c|c|c|c|c|c|}
\hline Gene & Position $^{1}$ & Genome $^{2}$ & $\begin{array}{l}\text { Linked } \\
\text { allele }\end{array}$ & $\begin{array}{l}\text { Predicted } \\
\text { AA change }\end{array}$ & rs number & $\begin{array}{c}\text { MAF }^{3} \text { in control } \\
\text { individuals }\end{array}$ \\
\hline$A T G 9 A$ & 5'RR & g.70303966G $>A$ & A & - & - & $17.8 \%$ \\
\hline$A N K Z F 1$ & Exon1 & g.70303966G $>A$ & A & - & - & $17.8 \%$ \\
\hline \multirow[t]{3}{*}{ DNAJB2 } & IVS1 & g.70353826G $>C$ & $\mathrm{C}$ & - & rs908197 & $20.5 \%$ \\
\hline & IVS2 & g.70354702C $>\mathrm{T}$ & $\mathrm{T}$ & - & rs2276638 & $19.6 \%$ \\
\hline & IVS6 & g.70357148C $>\mathrm{T}$ & $\mathrm{T}$ & - & rs2276639 & $19.6 \%$ \\
\hline \multirow[t]{2}{*}{ OBSL1 } & Exon $15 b$ & g.70629303G $>A$ & A & - & - & $0.6 \%$ \\
\hline & Exon 15 & g.70630338C $>\mathrm{T}$ & $\mathrm{T}$ & p.Ala1477Thr & - & $0.9 \%$ \\
\hline
\end{tabular}

${ }^{1} \mathrm{RR}$ : regulatory region; IVS: intervening sequence.

${ }^{2}$ Numbering relative to NT_005403.16 and starting at nucleotide 1.

${ }^{3}$ MAF: Minor allele frequency.
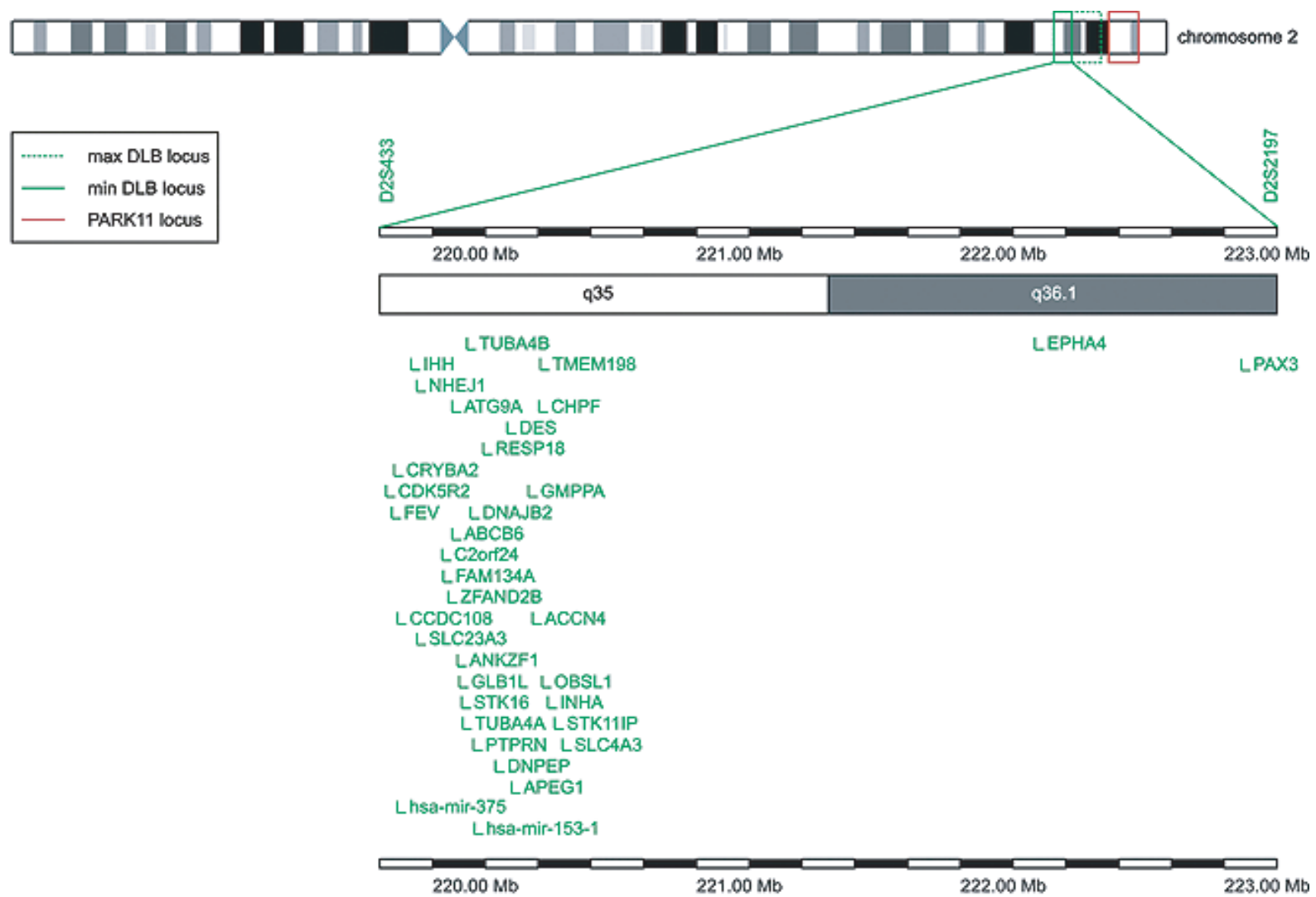

Fig. 3. Schematic presentation of the DLB locus on chromosome $2 \mathrm{q}$. The green box with dotted lines represents the maximal candidate $9.2 \mathrm{Mb}$ region at 2q35-q36 as previously described [3]. The green box with full lines depicts the minimal $3.3 \mathrm{Mb}$ linked region based on a centromeric (II.8) and telomeric (II.11) recombinant in family DR246. Protein-coding and miRNA genes within this region are inferred from the Ensemb1 Genome Browser.

age scan. Subsequent genetic finemapping of suggestive candidate loci identified significant linkage with a maximum LOD score of 3.01 at D2S1242 and a maximal candidate region of $9.2 \mathrm{Mb}$ within chromosome band 2q35-q36 [3]. Here, we expanded the DLB family by sampling additional family members for linkage studies in the DLB locus. We were able to confirm the linkage and to significantly reduce the size of the DLB locus to $3.3 \mathrm{Mb}$ based on one new meiotic recombinant in an at-risk sibling (II.11, aged 91 years) and child (III.24, aged 58 years) (Figs 1 and 2). The current age of the healthy sibling (II.11) exceeded the mean onset age of 70.7 years in family DR246 by more than three standard deviations. 
Considering a putative role in the pathogenesis of DLB, we systematically selected candidate genes for mutation analyses. In contrast to many other studies, we did not limit our standard sequencing approach to coding exons and exon-intron boundaries. We also included untranslated and proximal regulatory regions because variations in these regions have been associated with disease [29-31]. Ultimately, we analyzed all known as well as predicted genes extensively but did not identify a disease-causing mutation which could explain the disease in family DR246. Since more complex dosage effects have been associated with other neurodegenerative brain diseases like $\mathrm{AD}$ ( $A \beta P P$ duplication [32]) and PD [33], we tested for a DLB-related CNV in DR246 by conducting array-CGH experiments. We designed a very high density $\mathrm{CNV}$ array with $>$ 150.000 overlapping probes covering the entire $3.3 \mathrm{Mb}$ linked region to enable the detection of possible $\mathrm{CN}$ Vs as small as 100 bp. Despite these efforts, we could not observe a causal CNV explaining the conclusive linkage peak at 2q35-q36.

While a comprehensive gene-based sequencing strategy is an acceptable first-phase approach to identify causal mutations in candidate regions, it is limited to the detection of "classic" small-scale mutations known to cause monogenic disorders (i.e., missense mutations, nonsense mutations, mutations affecting the consensus splice-sites, and frameshift mutations due to small indels). Moreover, exonic, exon boundaries and proximal regulatory sequences constitute only a negligible part of the genomic sequence, leaving the majority of the candidate region unanalyzed. Once regarded as junk DNA, intronic and intergenic sequences are now perceived to contain crucial splicing machinery elements and other gene expression regulating motifs. Recently, several studies have shown that mutations disturbing these important elements can lead to disease [34-37]. Therefore, we expect that high throughput sequencing of the entire $3.3 \mathrm{Mb}$ candidate region might reveal a more complex mutation associated with DLB in family DR246. These complex mutations might explain the numerous chromosomal regions in which significant linkage peaks have been detected without the identification of the pathogenic mutation.

In conclusion, our data emphasized the genetic heterogeneity of DLB and strongly supported the existence of a gene for familial DLB in 2q35-q36. The identification of the underlying complex genetic defect will reveal the first novel causal gene for DLB. Of interest, Lewy body pathology has also been reported to be present in a substantial number of AD brains and, vice versa, AD pathology has been detected to various extent in autopsied DLB brains [38], suggesting either overlapping or interacting pathogenic mechanisms. Therefore, we are convinced that the study of the mutation spectrum of this novel gene in DLB and other neurodegenerative brain diseases with overlapping clinical and/or pathological features, such as AD, will not only provide a better understanding of the molecular pathogenic cascades of these diseases but might also highlight important mechanistic links between them.

\section{ACKNOWLEDGMENTS}

We are grateful to the participants of this study for their kind cooperation and to the personnel of the VIB Genetic Service Facility (http://www.vibgeneticser vicefacility.be) and the Biobank of the Institute BornBunge. This research was supported by the Special Research Fund of the University of Antwerp, the Fund for Scientific Research Flanders (FWO-V), the Institute for the promotion of Innovation by Science and Technology in Flanders (IWT-V), the Foundation for Alzheimer Research (SAO/FRMA), the Interuniversity Attraction Poles (IAP) Program P6/43 of the Belgian Federal Science Policy Office, a Methusalem Excellence Grant of the Flanders Government and the Medical Research Foundation Antwerp and Neurosearch, Antwerp, Belgium, and the Alzheimer's Association USA. B.M. and K.N. are holders of a PhD fellowship of the IWT-V, and J.T. receives a FWO-V postdoctoral fellowship, Belgium.

Authors' disclosures available online (http://www.jalz.com/disclosures/view.php?id=233).

\section{REFERENCES}

[1] McKeith IG, Galasko D, Kosaka K, Perry EK, Dickson DW, Hansen LA, Salmon DP, Lowe J, Mirra SS, Byrne EJ, Lennox G, Quinn NP, Edwardson JA, Ince PG, Bergeron C, Burns A, Miller BL, Lovestone S, Collerton D, Jansen EN, Ballard C, de Vos RA, Wilcock GK, Jellinger KA, Perry RH (1996) Consensus guidelines for the clinical and pathologic diagnosis of dementia with Lewy bodies (DLB): report of the consortium on DLB international workshop. Neurology 47, 1113-1124.

[2] Zaccai J, McCracken C, Brayne C (2005) A systematic review of prevalence and incidence studies of dementia with Lewy bodies. Age Ageing 34, 561-566.

[3] Bogaerts V, Engelborghs S, Kumar-Singh S, Goossens D, Pickut B, van der ZJ, Sleegers K, Peeters K, Martin JJ, Del Favero J, Gasser T, Dickson DW, Wszolek ZK, De Deyn PP, Theuns J, Van Broeckhoven C (2007) A novel locus for dementia with Lewy bodies: a clinically and genetically heterogeneous disorder. Brain 130, 2277-2291. 
[4] Denson MA, Wszolek ZK, Pfeiffer RF, Wszolek EK, Paschall TM, McComb RD (1997) Familial parkinsonism, dementia, and Lewy body disease: study of family G. Ann Neurol 42, 638-643.

[5] Galvin JE, Lee SL, Perry A, Havlioglu N, McKeel DW, Jr., Morris JC (2002) Familial dementia with Lewy bodies: clinicopathologic analysis of two kindreds. Neurology 59, 10791082.

[6] Golbe LI, Di Iorio G, Bonavita V, Miller DC, Duvoisin RC (1990) A large kindred with autosomal dominant Parkinson's disease. Ann Neurol 27, 276-282.

[7] Tsuang DW, Dalan AM, Eugenio CJ, Poorkaj P, Limprasert P, La Spada AR, Steinbart EJ, Bird TD, Leverenz JB (2002) Familial dementia with lewy bodies: a clinical and neuropathological study of 2 families. Arch Neurol 59, 1622-1630.

[8] Waters CH, Miller CA (1994) Autosomal dominant Lewy body parkinsonism in a four-generation family. Ann Neurol 35, 59-64.

[9] Ohara K, Takauchi S, Kokai M, Morimura Y, Nakajima T, Morita Y (1999) Familial dementia with Lewy bodies (DLB). Clin Neuropathol 18, 232-239.

[10] Guyant-Marechal I, Berger E, Laquerriere A, Rovelet-Lecrux A, Viennet G, Frebourg T, Rumbach L, Campion D, Hannequin D (2008) Intrafamilial diversity of phenotype associated with app duplication. Neurology 71, 1925-1926.

[11] Ishikawa A, Piao YS, Miyashita A, Kuwano R, Onodera O, Ohtake H, Suzuki M, Nishizawa M, Takahashi H (2005) A mutant PSEN1 causes dementia with Lewy bodies and variant Alzheimer's disease. Ann Neurol 57, 429-434.

[12] Piscopo P, Marcon G, Piras MR, Crestini A, Campeggi LM, Deiana E, Cherchi R, Tanda F, Deplano A, Vanacore N, Tagliavini F, Pocchiari M, Giaccone G, Confaloni A (2008) A novel PSEN2 mutation associated with a peculiar phenotype. Neurology 70, 1549-1554.

[13] Koide T, Ohtake H, Nakajima T, Furukawa H, Sakai K, Kamei H, Makifuchi T, Fukuhara N (2002) A patient with dementia with Lewy bodies and codon 232 mutation of PRNP. Neurology 59, 1619-1621.

[14] Morfis L, Cordato DJ (2006) Dementia with Lewy bodies in an elderly Greek male due to alpha-synuclein gene mutation. J Clin Neurosci 13, 942-944.

[15] Singleton AB, Farrer M, Johnson J, Singleton A, Hague S, Kachergus J, Hulihan M, Peuralinna T, Dutra A, Nussbaum R, Lincoln S, Crawley A, Hanson M, Maraganore D, Adler C, Cookson MR, Muenter M, Baptista M, Miller D, Blancato J, Hardy J, Gwinn-Hardy K (2003) alpha-Synuclein locus triplication causes Parkinson's disease. Science 302, 841.

[16] Zarranz JJ, Alegre J, Gomez-Esteban JC, Lezcano E, Ros R, Ampuero I, Vidal L, Hoenicka J, Rodriguez O, Atares B, Llorens V, Gomez TE, del Ser T, Munoz DG, de Yebenes JG (2004) The new mutation, E46K, of alpha-synuclein causes Parkinson and Lewy body dementia. Ann Neurol 55, 164-173.

[17] Ohtake H, Limprasert P, Fan Y, Onodera O, Kakita A, Takahashi H, Bonner LT, Tsuang DW, Murray IV, Lee VM, Trojanowski JQ, Ishikawa A, Idezuka J, Murata M, Toda T, Bird TD, Leverenz JB, Tsuji S, La Spada AR (2004) Beta-synuclein gene alterations in dementia with Lewy bodies. Neurology 63 , 805-811.

[18] Haubenberger D, Bonelli S, Hotzy C, Leitner P, Lichtner P, Samal D, Katzenschlager R, Djamshidian A, Brucke T, Steffelbauer M, Bancher C, Grossmann J, Ransmayr G, Strom TM, Meitinger T, Gasser T, Auff E, Zimprich A (2007) A novel LRRK2 mutation in an Austrian cohort of patients with Parkinson's disease. Mov Disord 22, 1640-1643.
[19] Ross OA, Toft M, Whittle AJ, Johnson JL, Papapetropoulos S, Mash DC, Litvan I, Gordon MF, Wszolek ZK, Farrer MJ, Dickson DW (2006) Lrrk2 and Lewy body disease. Ann Neurol 59, 388-393.

[20] Clark LN, Kartsaklis LA, Wolf GR, Dorado B, Ross BM, Kisselev S, Verbitsky M, Mejia-Santana H, Cote LJ, Andrews H, Vonsattel JP, Fahn S, Mayeux R, Honig LS, Marder K (2009) Association of glucocerebrosidase mutations with dementia with lewy bodies. Arch Neurol 66, 578-583.

[21] Farrer MJ, Williams LN, Algom AA, Kachergus J, Hulihan MM, Ross OA, Rajput A, Papapetropoulos S, Mash DC, Dickson DW (2008) Glucosidase-beta variations and Lewy body disorders. Parkinsonism Relat Disord 15, 414-416.

[22] Goker-Alpan O, Giasson BI, Eblan MJ, Nguyen J, Hurtig HI, Lee VM, Trojanowski JQ, Sidransky E (2006) Glucocerebrosidase mutations are an important risk factor for Lewy body disorders. Neurology 67, 908-910.

[23] Mata IF, Samii A, Schneer SH, Roberts JW, Griffith A, Leis BC, Schellenberg GD, Sidransky E, Bird TD, Leverenz JB, Tsuang D, Zabetian CP (2008) Glucocerebrosidase gene mutations: a risk factor for Lewy body disorders. Arch Neurol $\mathbf{6 5}$, 379-382.

[24] O'Connell JR, Weeks DE (1998) PedCheck: a program for identification of genotype incompatibilities in linkage analysis. Am J Hum Genet 63, 259-266.

[25] Lathrop GM, Lalouel JM, Julier C, Ott J (1985) Multilocus linkage analysis in humans: detection of linkage and estimation of recombination. Am J Hum Genet 37, 482-498.

[26] Aerts S, Lambrechts D, Maity S, Van Loo P, Coessens B, De Smet F, Tranchevent LC, De Moor B, Marynen P, Hassan B, Carmeliet P, Moreau Y (2006) Gene prioritization through genomic data fusion. Nat Biotechnol 24, 537-544.

[27] Weckx S, Del Favero J, Rademakers R, Claes L, Cruts M, De Jonghe P, Van Broeckhoven C, De Rijk P (2005) novoSNP, a novel computational tool for sequence variation discovery. Genome Res 15, 436-442.

[28] van de Wiel MA, Kim KI, Vosse SJ, van Wieringen WN, Wilting SM, Ylstra B (2007) CGHcall: calling aberrations for array CGH tumor profiles. Bioinformatics 23, 892-894.

[29] Theuns J, Del-Favero J, Dermaut B, van Duijn CM, Backhovens H, Van den Broeck M, Serneels S, Corsmit E, Van Broeckhoven C, Cruts M (2000) Genetic variability in the regulatory region of presenilin 1 associated with risk for Alzheimer's disease and variable expression. Hum Mol Genet 9, 325-331.

[30] Theuns J, Brouwers N, Engelborghs S, Sleegers K, Bogaerts V, Corsmit E, De Pooter T, van Duijn CM, De Deyn PP, Van Broeckhoven C (2006) Promoter mutations that increase amyloid precursor-protein expression are associated with Alzheimer disease. Am J Hum Genet 78, 936-946.

[31] Brouwers N, Sleegers K, Engelborghs S, Bogaerts V, Serneels S, Kamali K, Corsmit E, De Leenheir E, Martin JJ, De Deyn PP, Van Broeckhoven C, Theuns J (2006) Genetic risk and transcriptional variability of amyloid precursor protein in Alzheimer's disease. Brain 129, 2984-2991.

[32] Sleegers K, Brouwers N, Gijselinck I, Theuns J, Goossens D, Wauters J, Del Favero J, Cruts M, van Duijn CM, Van Broeckhoven C (2006) APP duplication is sufficient to cause early onset Alzheimer's dementia with cerebral amyloid angiopathy. Brain 129, 2977-2983.

[33] Nuytemans K, Meeus B, Crosiers D, Brouwers N, Goossens D, Engelborghs S, Pals P, Pickut B, Van den Broeck M, Corsmit E, Cras P, De Deyn PP, Del-Favero J, Van BC, Theuns J (2009) Relative contribution of simple mutations vs. copy number 
variations in five Parkinson disease genes in the Belgian population. Hum Mutat 30, 1054-1061.

[34] Benko S, Fantes JA, Amiel J, Kleinjan DJ, Thomas S, Ramsay J, Jamshidi N, Essafi A, Heaney S, Gordon CT, McBride D, Golzio C, Fisher M, Perry P, Abadie V, Ayuso C, HolderEspinasse M, Kilpatrick N, Lees MM, Picard A, Temple IK, Thomas P, Vazquez MP, Vekemans M, Crollius HR, Hastie ND, Munnich A, Etchevers HC, Pelet A, Farlie PG, Fitzpatrick DR, Lyonnet S (2009) Highly conserved non-coding elements on either side of SOX9 associated with Pierre Robin sequence. Nat Genet 41, 359-364.

[35] Davis RL, Homer VM, George PM, Brennan SO (2009) A deep intronic mutation in FGB creates a consensus exonic splicing enhancer motif that results in afibrinogenemia caused by aberrant mRNA splicing, which can be corrected in vitro with antisense oligonucleotide treatment. Hum Mutat 30, 221227.
[36] Pros E, Fernandez-Rodriguez J, Canet B, Benito L, Sanchez A, Benavides A, Ramos FJ, Lopez-Ariztegui MA, Capella G, Blanco I, Serra E, Lazaro C (2009) Antisense therapeutics for neurofibromatosis type 1 caused by deep intronic mutations. Hum Mutat 30, 454-462.

[37] Vega AI, Perez-Cerda C, Desviat LR, Matthijs G, Ugarte M, Perez B (2009) Functional analysis of three splicing mutations identified in the PMM2 gene: toward a new therapy for congenital disorder of glycosylation type Ia. Hum Mutat 30,795-803.

[38] Marui W, Iseki E, Kato M, Akatsu H, Kosaka K (2004) Pathological entity of dementia with Lewy bodies and its differentiation from Alzheimer's disease. Acta Neuropathol 108, 121-128. 